\title{
A Decade of Research on the Effectiveness of Augmented Reality on Students with Special Disability in Higher Education
}

\author{
Malek Turki Jdaitawi \\ Imam Abdulrahman Bin Faisal University, Saudi Arabia \\ ORCID: 0000-0001-7536-1933 \\ Ashraf F Kan'an \\ Irbid National University, Jordan \\ ORCID: 0000-0003-2258-9496
}

Received: 21 Jun 2021

Accepted: 22 Sep 2021

\begin{abstract}
In higher education settings, students are required to use their own devices to record attendance interact with classes through online systems and other learning-teaching sources such as timetables, virtual learning environment. Real opportunity to use digital technology such as augmented reality AR technology have been used in several fields, uncovering diverse benefits regarding its usage. However, further research is needed to understand exactly how the AR enhance students learning. Focusing on individuals with special needs, AR is being used in higher education for the last few years to enhance physical, cognitive, personal, and social abilities. This systematic review presented an overview of the usage of AR technology in the special needs area in higher education literature published between 2011 and 2020 and focused on research indexed in 8 international databases. 36 studies were included for review. The results indicate that the majority of research showed positive outcomes as the AR technology proved to be effective with students with disabilities. The results also showed that AR technology was mostly used in intellectual disability setting. Finally, the result evidenced that AR assists students in enhancing their social skills, social relationships and their engagement. The results from this systematic review provide valuable information regarding to enhance individual with special needs. Future empirical research should ensure that all research is included, including settings, level of students and data collection methods such as quantitative and qualitative.
\end{abstract}

Keywords: special needs, disability, augmented reality, systematic review

\section{INTRODUCTION}

In the current times, the concept of inclusive education is concerned with each individual right to receive education based on their learning needs (Lindsay, 2018; Westwood \& Graham, 2009). In terms of education, the processes involved in meeting the various needs of individuals have gone through evolution since its inception from a moralistic point of view (Quiroga, 2010) to a special education concept (for physically, psychologically or emotionally challenged individuals), to which traditional teaching cannot be used on (Araque \& Barrio 2010). More importantly, special education calls for distinct teaching strategies for the learning and skill acquisition facilitation of students suffering from learning disabilities, and disorders (communication, behavioral and development) (Cifuentes et al., 2016). Students with disabilities have been the focus of educational reform in the past several decades (Awada, 2014). Various individuals around the globe with cognitive and physical disorders need assistance and special care in their processes of learning (Adam \& Tatnall, 2017; Eldenfria \& Al-Samarraie, 2019). According to the findings of Browder et al.'s (2008), 
more effective methods and practices should be provided to disabled people having special education needs in the fields of education and several teaching techniques have been proposed to this end.

More recently, digital technology developed have led to various learning options and alternatives in the education field and along with it, are innovative changes of learning and teaching (Collins \& Halverson, 2009; Jdaitawi, 2019, 2020a, 2020b). The innumerable changes occurring in the educational environment stems from wireless network technology, the use of media in different settings and new teaching techniques using new technologies. From the teaching methods, augmented reality are the ones standing out and garnering educational research in bulks (Kellems et al., 2019; Khan et al., 2019; Savelsbergh et al., 2016). Augmented reality (AR) basically enables the combination of teaching methods were students have traditional learning from materials coupled with visualizations of the processes involved (Sugiura et al., 2018) or provide interaction between real-world objects and the digital visualization (Behmke et al., 2018), as the digital information can be presented in the real world directly to the user without requiring the later to pay explicit attention to the screen of a device (Kun et al., 2019) and superimposition of real actual objects with information and virtual objects (Azuma et al., 2011). Along with this is the delimitation of AR in terms of sense of sight but also extend to all senses (hearing, smell and even touch) (Rizov \& Rizov, 2015), making it a promising technique to facilitate educational inclusion processes (Sheehy et al., 2014). This is because it is represented via several means of action and students' learning engagement processes (Meyer et al., 2014).

The advancement of digital technology has a direct influence on higher education. Consequently, the educational actions proposed by institutions of higher education must consider the rate at which these technologies evolve (Kyza \& Georgiou, 2018; Sirakaya \& Sirakaya, 2020). In this order of ideas, the application of AR have facilitated developing competences derived from the use of ICT, such as teamwork capacity, and discovering new didactic resources related to immersive technology that enable the development of new teaching processes from an inquiring and ubiquitous perspective (Mthembu, 2018; Sampaio \& Almeida, 2016). AR applications in education have a significant contribution to the area of knowledge, as they contribute to facilitating the teaching of didactic content that would otherwise be more difficult to transmit. Therefore, the inclusion of this technology in educational practices favours obtaining better quality standards (Diao \& Shih, 2019). AR technology is used in the field of higher education to promote student learning, so that it becomes a tool that allows you to observe physical elements of reality through mobile devices through a fun and playful interaction facilitating study of the contents (Abad Segura et al., 2020).

$A R$ is deemed to be a technology with promising possibilities when it comes to teaching and learning, increasing students' (with and without disabilities) success (Carreon et al., 2019; Kellems et al., 2019) and influence student motivation and their engagement (Bacca et al., 2018). Studies reported that AR technology can promote teaching and learning, resulting in enhanced achievement, motivation, improved perception, confidence, increase independence and daily life skills, spatial ability, interest, engagement and ultimately, satisfaction (Akcayir \& Akcayir, 2017; Bacca et al., 2018; Bridges et al., 2020; McMahon, 2015).

In literature, studies have highlighted the AR contributions towards the process of learning and its facilitation of integration of disabled individuals into the community and improving their social skills (Cate et al., 2017; Cakir \& Korkmaz, 2019; Lorenzo et al., 2019). This is made possible through the mixed-environment nature that AR technology provides, which allows the integration of actual interaction of virtual objects with real objects (Chen et al., 2015). Added to this, AR applications offer various characteristics that immerse, interact, and involve disability-specific social services including social living and relevant learning as well as physical services (Huang et al., 2019; Lorenzo et al., 2019; Zhao et al., 2018). The current research presents the potential benefits of AR application in special education for individuals with disabilities, with the inclusion of autism and spectrum disorder, individuals with hearing impairments, and those with cognitive and physical disorders (Bacca et al. 2018; Bridges et al., 2020; Huang et al., 2019; Lorenzo et al., 2019; Zhao et al., 2018). To begin with, Bridges et al. (2020) who confirmed that AR increase daily and independence skills among special need students. Also, McMahon (2015) indicated that AR technology leads to improved learning among special needs students. Zhao et al. (2018) related that AR technology facilitating students with low vision understanding. In the same study caliber, Huang et al. (2019) indicted that AR is a supported tool for user with reduced vision, and Lorenzo et al. (2019) revealed the possibility of AR in increasing vocabulary 
knowledge among students with disabilities. Cate et al. (2017) also highlighted the solving problem difficulties in teaching students with individual with intellectual disabilities, hence, AR was suggested as a good strategy to develop wayfinding skills as a mean to increase the functional capabilities of individuals with intellectual disabilities. AR can also be used to assist in meeting the needs of students in real time, clarifies knowledge and maximizes the students' attention towards learning, as well as developed communication skills among students with ASD and facilitated their motivation and interaction skills (Pradibta, 2018; Taryadi \& Kurniawan, 2018; Walker et al., 2017).

Due to the high demand of tools and methods for special needs education, teachers, engineers, researchers, and practitioners have been developing techniques that involve $A R$ and that enriches learning and teaching experiences in this context. Nevertheless, Quintero et al. (2019) highlighted that AR studies have not yet deeply explored and remained stagnant in comparison to those dedicated to other technologies in education and in special education (Baragash et al., 2020; Bridges et al., 2020; Gomez-Puerta et al., 2019; Huang et al., 2019), leading to the need to examine the level to which AR affects learning of individuals with special needs, in terms of various skills (Baragash et al., 2020; Quintero et al., 2019). Along with this is the necessity to conduct an analysis of the potential of AR to assist students suffering with learning disabilities (Quintero et al., 2019). Therefore, in the present study, studies dedicated to topic are reviewed, particularly 16 studies obtained from several databases. The thorough review aims to present the literature analysis outcome relating to $A R$ and students with disabilities in higher education settings. The review also aims to provide the pros and cons, conclusions, and challenges within the AR field when it comes to students with disabilities in higher education settings.

\section{Augmented Reality (AR) in Education}

AR paves the way for students to practice knowledge and skills through the seamless combination of digital information with actual real-world surroundings (Wojciechowski \& Cellary, 2013). It also enables practicing skills and knowledge on real-world instances and provides interactive learning environments via activities of the same caliber (Chen et al., 2015). In fact, AR have been reported to facilitate time and cost-saving in highcost educational sector (Gavish et al., 2015). According to Tekedere and Hoker (2016), AR technology is among the technologies that loads and merges virtual objects with the actual images through video, sound, photography, text, 3D models, among other techniques and it is deemed to be extended from virtual reality. A key distinction between the two is that $A R$, unlike VR, provides the users with suitable interface merging the real with the online world (Tekedere \& Hoker, 2016). It facilitates the interaction of users and virtual objects that are positioned in actual scenes creating experiences in natural and virtual interactions (Cai et al., 2014). In sum, AR applications primarily aim to function as a medium that functions in the real world to satisfy the needs of users (Tekedere \& Hoker, 2016).

Moreover, AR incorporates digital information into real environment through the combination of the two realms (Dalgarno \& Lee 2010; Quandt et al., 2018), and paves the way for learning opportunities, integrated with mobile applications and mobile devices to bring about interactive learning. In this regard, increased interactivity is maintained as AR supports new interaction learner-tools (Diegman et al., 2015). In the study line, Radu (2012) examined the way AR in education contributes to learning effects including, increased content understanding, enhanced long-term memory retention and increased motivation and self-learning of students (cited in Quqandi et al., 2018). Meanwhile literature revealed that AR technology have a significant effect on the problem solving, motivation and learning outcomes of students, which was supported by Oranc and Kuntay (2019), Deshpande and Kim (2018), and Karagozlu (2018). Moreover, AR systems enable integration of features into the lecture notes of instructors (Ozdemir et al., 2018), which means abstract information can be instructed to the students concretely. AR enables the observation of events that cannot be easily observed in real life (Wu et al., 2013) and as such, the top AR advantages to education is to facilitate a comprehensive blended learning environment that encourages critical thinking, problem solving and cooperative communicative skills through digital and physical objects in combination in one environment (Dunleavy et al., 2009; Ozdemir et al., 2018). 
Using AR in the educational field shows that prior applications using AR in education positively affected the learning process (Cai et al., 2014; Ibanez et al., 2014). AR technology also makes it possible to display events and dangerous experiments which are rarely observable in the actual world of traditional learning. This transforms abstract subjects into concrete ones providing practical experiences to the students (Shelton \& Hedley, 2002). Cai et al. (2014) reported that several studies in literature focused on the AR technology use in teaching chemistry, while others (Sommerauer \& Muller, 2014) focused on teaching mathematics and geometry. Some others like Chang et al. (2014) focused on natural sciences, Ibanez, et al. (2014), Cai et al. (2013) and Lin et al. (2013) focused on teaching physics, and finally other authors tackled the AR's role in increasing the academic levels of success and motivations among students (e.g., Di-Serio et al., 2013; FerrerTorregrasa et al., 2015; Martin-Gutierrez \& Fernandez, 2014).

\section{Augmented Reality in Special Education in Higher Education Setting}

In recent times, AR applications have been extensively examined and used to facilitate and integrate individuals with disabilities into the community they live in (Cakir \& Korkmaz, 2019). AR applications make this possible through mixed-environments that allow the combination of actual objects with virtual ones (Chen et al., 2015) and providing various immersion, interaction and involvement features for disabilitycentered social services in the form of social living and physical and learning services (Wu et al., 2013). Basically, individuals with disabilities as described in Leonardi et al. (2006), are those who have long-term physical, mental, intellectual or sensory impairments, which through the barriers in interaction may prevent them from fully participating in society at par with the rest of the individuals without disabilities (p. 1220). A thorough review of literature on AR application in special education revealed AR's role in supporting learning among individuals with disabilities in terms of self-determination and self-management, self-instruction guidance in the resolution of complex tasks, and guidance to different environments (Gomez-Puerta et al., 2019). AR technology may also be useful in improving special needs students' learning (Sirakaya \& Sirakaya, 2018; Yuliono \& Rintayati, 2018). Studies along this line include Benda et al. (2015) and Smith et al. (2015) study's that supported the great potential effect of augmented reality technology on display educational materials that proven to be great tool to improved experience in learning such as navigation skills among adult with intellectual disability. In addition, Huang et al. (2019) conducted a study concerning the application of augmented reality as a reading assistant tool among individuals with reduced vision, and the results demonstrated that AR have the potential to enhance their vision. Among such studies is by Bridges et al. (2020) that addressed the development of daily living skills using augmented reality to adult with intellectual disabilities. The findings showed that intervention activities were effective for increasing daily living skills such as independence skill. AR teaching material is in fact suitable and useful in contributing to the learning development of individuals with cognitive impairments. In their study Chang et al. (2014) indicated that the participants increased their target response, which improved their vocational job skills during the intervention phases and enabled them to maintain the acquired job skills after intervention.

\section{Purpose of the Study}

Literature indicated a gap of studies concerning an intensive review of the AR factors in educational field and context and considering this fact, the present study conducted a systematic literature review to unearth the current status of AR in higher education setting among individuals with disability. The present study also took categories of analysis of the current status and tendencies of AR, like its uses in the educational context, advantages, limitations, effectiveness and the availability of adaptation and personalization in its applications, particularly those addressing students who have special needs. Analyzing various categories enables the highlight on emerging trends, challenges and opportunities and extended research and vision towards the future outcomes and goals. The application of AR in special education was thus examined based on the following research questions:

1. What is the effect of AR on assisting special needs students in their learning outcomes?

2. What is the top common special needs field for AR in higher education? 
3. What are the advantages, limitations, and challenges of $A R$ in special education and suggestion trends in the use of AR in such context?

\section{METHODOLOGY}

In this study, a 4-phased process of systematic review of relevant studies was adopted from Arksey and O'Malley (2005), and Kitchenham (2004).

\section{Identification of Research Questions}

The study first highlighted the trends in educational AR studies carried out for the years 2011 to 2020, after which, the research questions were formulated following the review, and categorized under the heading "the purpose of the study".

\section{Identification of Relevant Studies}

AR usage in educational environments is a topic of research that has increased in focus and popularity only recently, which goes to say that there are limited studies that tackled it in literature (Akcayir \& Akcayir, 2017; Bacca et al., 2014; Cheng \& Tsai, 2013; Radu, 2014). Arksey and O'Malley (2005), and Kitchenham (2004) laid down the exclusion and inclusion conditions for the studies examined for the years from 2010 to 2020 . The studies examined were found in selected on the basis of journals, methods or research topics, data analysis, findings, limitations, advantages and disadvantages of AR and conclusion. An extensive and robust systematic review was conducted to identify the educational $A R$ studies trends and thus this necessitated the examination of articles from various databases, including ERIC, EBSCOhost, dissertation, ScienceDirect, Scopus, Elsevier and ISI databases. The keyword primarily used was 'augmented reality' to search for the studies in the databases, accessing a higher number of such studies in different fields and levels.

\section{Inclusion/Exclusion (Study Selection)}

A total of 16 articles were obtained out of 36 articles from the above-mentioned databases and were considered to be suitable for the study purpose based on thorough assessment. The studies were categorized by author name, variables, and special needs (study content) as well as their results and findings (study data). The initial search yielded 36 records. Applying the inclusion/exclusion criteria (inclusion: published between 2011-2020, English language, students with disability, AR technology, indexed in ERIC, EBSCOhost, dissertation, ScienceDirect, Scopus, Elsevier and ISI databases; Exclusion: published before 2011, not in English, not students with disability, other databases), 16 articles were included in this study.

\section{Results and Discussion}

This necessitated the consideration of the research questions, which are; 1 ) What is the effect of AR on assisting special needs students in their learning outcomes in higher education setting? 2) What is the top common special needs field for AR in higher education? 3) What are the advantages, limitations, and challenges of $A R$ in special education and suggestion trends in the use of $A R$ in such context?

\section{RESULTS AND DISCUSSION}

With regards to the first question (AR outcomes), the results garnered from the coding process of data in the special education settings are tabulated in Table 1, where the use of AR in each field of special education are listed. The reviewed studies indicated that the AR technology proved to be effective with students with disabilities in the higher education setting.

With regards to the second question, the results garnered from the coding process of data in the special education settings are tabulated in Table 2, where the use of AR in each field of special education are listed. The top outstanding outcome to arise from data is that majority of the studies (43.75\%) were conducted in the intellectual disability field. This may be related to the purpose of individuals intellectual ability 
Table 1. A summary of the 16 studies found applying AR for individual with disabilities

\begin{tabular}{|c|c|c|c|}
\hline Special Needs & Authors & Variable & Positive Outcome \\
\hline \multirow[t]{2}{*}{ Visual Impairments } & Huang et al. (2019) & supported tool for user with reduced vision & Yes \\
\hline & Zhao et al. (2018) & understanding low vision people visual perception & Yes \\
\hline \multirow[t]{3}{*}{ Autism } & McMahon et al. (2015) & increase science vocabulary knowledge & Yes \\
\hline & McMahon et al. (2015) & support decision making & Yes \\
\hline & Lorenzo et al. (2019) & improve social skills & Yes \\
\hline \multirow[t]{2}{*}{ General Special Needs } & Lorenzo (2019) & enhance competitive in the job market & Yes \\
\hline & McMahon (2015) & improve the academic skills of students & Yes \\
\hline Intellectual & Cate et al. (2017) & improve navigation skills & Yes \\
\hline \multirow[t]{6}{*}{ Disabilities } & Cacciator (2018) & enhanced mathematics skills & Yes \\
\hline & Benda et al. (2015) & working aid tool & No \\
\hline & Smith et al. (2017) & improve navigation skills & Yes \\
\hline & McMahon et al. (2015) & increase knowledge & Yes \\
\hline & Bridges et al. (2020) & increase daily and independence skills & Yes \\
\hline & McMahon et al. (2013) & effective in identifying possible allergens & Yes \\
\hline Cognitive Disorders & Chang et al. (2013) & improve perception and vocational job skills & Yes \\
\hline Vocational Education & Bacca et al. (2018) & influence students motivation & Yes \\
\hline
\end{tabular}

development being their exposition to the required life skills and as such, AR was used for individual's engagement, particularly individuals with intellectual disabilities, for them to be able to learn positive behaviors, positively impacting their skills acquisition in real-life situations. Autism followed Intellectual disabilities as the second needs upon which AR was applied to (18.75\%). This may be attributed to the fact that AR have been extensively utilized in learning and social interaction skills as it is capable of combining such skills and learning with contextual information to furnish a novel experience in learning and improved social interaction through practice and motivation towards real-world experiences. Visual aid and general special needs fell third in line of the disabilities benefiting from AR technology (12.5\%) and (12.5\%) respectively. Studies showed that technology-supported activities were reported to influence the cognitive, behavioral, mental and physical development of students with disabilities (e.g., Cakir \& Korkmaz, 2019; Jones et al., 2020; McMahon et al., 2015). The rest of the disabilities and disorders that followed are cognitive $(6.25 \%)$ and vocational and training needs (6.25\%).

Moving on to the third question; 3) What are the advantages, limitations, and challenges of AR in special education in higher education setting and suggestion trends in the use of AR in such context? The advantages, limitations and challenges of AR obtained from the process of data coding in special education settings, are displayed in Table 1. From the table, the use if AR in each field of special education is listed and based on it, AR assists students in enhancing their social skills and social relationships, and it motivates them (Bacca et al., 2018; Lorenzo et al., 2019), while enhancing their skills of self-independence and their learning engagement (Bridges et al., 2020), and increasing their knowledge concerning vocabulary (McMahon et al., 2015), and their decision making skills (McMahon et al., 2015), as well as students' academic skills (McMahon et al., 2015). According to Chang et al. (2013), AR improved students' perception and vocational job skills among university students. According to other studies (e.g., Fridhi et al., 2018; Lin et al., 2016), AR also enhances learning motivation, bring about positive interest, behaviors and tolerance towards frustration, while others indicated its role in enhancing functional vision (e.g., Kinateder et al., 2018). The results may be related to the learning and social environment that supports social relations and interactions that facilitates the reaping of AR learning advantages. The learning environment increased peer and teacher interactions contribute to enhanced non-targeted skills development like language and appropriate behavior displayed by autistic students (Rogers, 2000; Watkins et al., 2018). Finally, students benefit from AR to enhance their perceptions of technology use in learning environments.

Other studies like Lorenzo et al. (2019) and Hornecker and Buur (2006) related that AR with autism students enhances their social skills and helps them to interact with their peers and involve in the active learning process. Still another AR benefit has been evidenced among individual with intellectual disabilities. Cacciator 
(2018) evidenced the positive effect of AR in transition-related math skills. This may be explained in light of the AR technology's role in assisting intellectual disabled individuals through providing support during activities. Moreover, AR enables visualization of pictures for decision-making. According to McMahon et al. (2015), AR experience among students allows them to view context-relevant prompts in the actual world, supporting their needs of decision-making. In other words, AR leads to positive outcomes among individual with intellectual disabilities. Special needs also generally benefit from AR technology, which could be because AR teaching materials work towards enriching education and towards amusing and interesting learning, catering to the interest of the students, enabling their view of real-life events. In the same line of study, Cakir and Korkmaz (2019) related the appropriateness and usefulness of AR in developing special education students, bringing to them real-life experiences, while increasing their individual's social interaction and environmental collaboration (with peers and teachers, etc). It can thus be concluded that AR is a potential tool to assist special needs individuals' learning and skills development (social and academic). Those with visual impairments may also leverage AR as a potential tool to help in learning. Huang et al. (2019) indicates that $A R$ is a supported tool for students with reduced vision, and Zhao et al. (2018) also indicated that AR increases the perception of students with low vision. Studies also supported that AR is a helpful tool for students with disabilities to be competitive in the job market (Lorenzo et al., 2019), and improves the academic and functional skills of the students with special needs (McMahon, 2015).

Moving on to the limitations of $A R$, the top limitation highlighted in literature in the special education category are as follows; AR needs to be developed based on the ability, skills of the students, age, and their background, rather than concentrating only on needs (Huang et al., 2019; McMahon et al., 2015; Smith et al., 2017). Also, studies mentioned that some AR application and types applicable for certain program but not for all programs (Bacca et al., 2018). Also, studies mentioned only examined limited participants (Bridges et al., 2020; McMahon et al., 2015; Smith et al., 2017), which beg the question of whether AR can be effective for a larger number of participants.

As for the challenges of AR technology, based on the study findings, AR activities design is a core challenge (e.g., Benda et al., 2015). This may be attributed to the challenge of activities design relating to the specialized devices or application required (McMahon et al., 2015). According to Klopfer and Squire (2008), and Wu et al. (2013), AR system should be integrated to other hardware and software devices, and in so doing, issues including interfacing between many devices and stability arise. Logistics is another challenge in the form of limited resources, locations, and the like (McMahon et al., 2015). Klopfer and Sheldon (2010) stated that the design of AR should be linked to real-world location as well as features that can relate to other contexts. Still another challenge is the AR features (Sahin et al., 2017; Zhao et al., 2018), which could be resolved through providing support to the user and developing a proper design in the learning environment. Added to the above, AR learning environment designers have to consider the gap and offer support towards instructors and students to minimize it. Another challenge reported by (Huang et al., 2019) that AR application requires a wireless internet connection, which may not be available in certain cases.

Moreover, Benda et al. (2015) highlighted another challenge in the form of learning using AR, which is a multi-task technology that could be difficult for some students to maneuver. The usability of the application is depending heavily on the individuals background and previous experiences (Benda et al., 2015). Dunleavy et al., (2009), and Wu et al. (2020) supported that students frequently displayed an overwhelming perception when they encounter AR simulation due to its unfamiliarity and due to the task's complexity.

\section{Discussion}

This study aimed at disclose the statues of empirical research on AR by using a systematic review approach. The results conclude that the AR in empirical terms is in the emergence of a research field. The following results could be derived which answer the research questions raised the beginning: 


\section{What is the effect of AR on assisting special needs students in their learning outcomes in higher education setting?}

Concerning the assisting learning outcomes among special needs students, more than half of all studies on $A R$ is primarily concluded that AR improved students learning outcomes. A possible explanation of the results is that AR have the potential to improved higher education students with disabilities skills such as increase knowledge, supported learning and perception, supportive tool for students with low vision, improve social skills, support decision making, improves the academic and functional skills, improve navigation skills, increase daily and independence and their motivation (Bacca et al., 2018; Benda et al., 2015; Bridges et al., 2020; Cate et al., 2017; Chang et al., 2013; Huang et al., 2019; Lorenzo et al., 2019; McMahon et al., 2015; Smith et al., 2017; Zhao et al., 2018). The current results extend the past systematic reviews, such as Baragash et al. (2020), and Barton et al. (2017) on the importance of assistive technology in facilitating the learning outcomes of individuals with special needs. The results of this study also supported the result of Garzon et al. (2019), and Cacciatore (2018) who confirmed the potential of AR in supporting the skills acquisition and learning skills of students with special needs. Based on these, it can be anticipated that students benefited from AR technology as it has the possibility of augmenting information and combining it with contextual information to provide new experiences in their learning (Bacca et al., 2014). The reviewed studies for students with disabilities in higher education were applied AR for motivating the students and enhance their experiences and engaging them to benefited from the advantage of the AR features. Another explanation is that the majority of the teaching-learning sessions is practical-based instruction and thus, computer assisted instruction is deemed to be an effective instruction method that students with special needs can avail from in these contexts. In a related study, Carnahan et al. (2012) revealed that technology integrated vocabulary instruction has a great potential to be used for students with disabilities. This study offers an important insight into the relative success of AR in promoting positive learning outcomes among students with special needs, and making great contributions towards the students personal, social and cognitive skills. It also offers research-based guidance to educators and decision makers for assisting students with special needs such as learning disabilities, cognitive disabilities etc.

\section{What is the top common special needs field for AR in higher education?}

The results of the systematic review seem to indicate that $A R$ is an important technology for all students with special needs. The review results noticed that AR is present not only in specific needs but also in learning disability, cognitive disability. Although, limited studies were dedicated to the positive effects of AR technology in the listed areas, and no investigation have delved in other disabilities type in higher education setting such as learning disabilities, Down syndrome, dyslexia and deaf, thus, the present results are significant in order to encourage and motivate future authors into exploring the AR usage and its positive effects in higher education setting with students with disabilities. The current results extend the past systematic reviews, such as Sirakaya and Sirakaya (2018) on the ability of assistive technology in in generating appropriate learning environments among special needs students. The result of this study shows that AR is a technology that can be implemented in special education of very diverse needs. On the basis of the finding, only limited studies were focused on special education needs, particularly those with visual impairments, cognitive disorders, learning disabilities and developmental disabilities, with most of them catering more towards individuals with autism. Nevertheless, AR technology held promising and positive effect on the special education needs and the results of this study are significant and recommend future studies to examine the above topics.

\section{What are the advantages, limitations, and challenges of $A R$ in special education and suggestion trends in the use of $A R$ in such context?}

AR technology is relatively new, and little has been stated concerning its operations and its full potential, and whether the objects required for intervention can make AR more efficient. Hence, limitations stem from purpose and time of activities. Development of AR application has to cater to the perception and needs of the user to provide information based on needs (Huang et al., 2019; Zhao et al., 2018). AR limitation also relates to the skill and ability of the user to use it and since it is a relatively new technology, it needs getting 
used to. Hence, AR technology development should be directed towards meeting learning needs of students, and it should be made flexible to enable the students' completion of the activities within in an easy manner. The current results extend the past systematic reviews, such as Giglioli et al. (2015), and Blattgerste et al. (2019) who focused on specific needs. Hence, AR technology development should be directed towards meeting learning needs of students, and it should be made flexible to enable the students' completion of the activities within in an easy manner. Nevertheless, AR technology held promising positive effect for students with special needs to learn different skills effectively and the results of this study are significant and recommend future studies to examine the above topics in special needs settings.

\section{CONCLUSION}

The present systematic review presented a thorough review of studies dedicated to the effectiveness of AR technology in its application in special education needs in higher education settings. Based on the findings, majority of the studies in literature supported positive outcomes and reinforced the potential of AR to contribute to and satisfy special education and its needs, particularly students with learning and other disabilities types. AR have also been evidenced to improve those with visual impairments and to promote social interaction among disabled individuals, motivating them and encouraging them to participate in social and daily activities. The results also revealed that the usefulness of AR in developing special education students, bringing to them real-life experiences, while increasing their individual's social interaction and environmental collaboration (with peers and teachers, etc). It can thus be concluded that AR is a potential tool to assist special needs individuals' learning and skills development (social and academic). Although, AR technology is useful to be implemented to assist individuals with disabilities to learn various skills to meet their needs and to motivate their engagement in society to lead a normal social life, literature highlighted that AR activities design is a core challenge as well as in the form of learning using AR, which is a multi-task technology that could be difficult for some students to maneuver.

\section{LIMITATIONS AND RECOMMENDATIONS}

The present systematic review has its limitations, the top among which is the number of studies examined from the main data sources based on the study objectives and as such, the findings may not apply to all published studies in the special education settings in higher education. The number of educational AR studies are increasing over the years, this study focused on the available studies so far, therefore, it can be argued that the results of this study is significant to guide future studies. Another limitation is the examined studies focus on enhancing specific skills of individuals with special education needs, in which case, future studies may address enhancing individual's skills to enhance their knowledge of science, math, computer and biology, or other fields. Examined studies mentioned disabilities that did not cover other disabilities, making for cautious generalization of results. Further to this, whilst the majority of research has been undertaken in English language and in higher education, there were some studies that did not indicate which type of settings were conducting their research in. It is important for authors to include as much information as possible, therefore, future studies are needed to direct their focus on the influence of AR on the above stated disabilities and those not covered in this study. Majority of the examined studies also included only limited participants in their experiments, necessitating future studies to cover large numbers of participants with various disabilities and disabilities levels.

Author contributions: All authors were involved in concept, design, collection of data, interpretation, writing, and critically revising the article. All authors approve final version of the article.

Funding: The authors received no financial support for the research and/or authorship of this article.

Declaration of interest: Authors declare no competing interest.

Data availability: Data generated or analysed during this study are available from the authors on request. 


\section{REFERENCES}

Abad-Segura, E., Gonzalez-Zamar, M., Rosa, A., \& Cevallos, M. (2020). Sustainability of educational technologies: An approach to augmented reality research. Sustainability, 12, 4091. https://doi.org/10.3390/su12104091

Adam, T., \& Tatnall, A. (2017). The value of using ICT in the education of school students with learning difficulties. Education and Information Technologies, 22(6), 2711-2726. https://doi.org/10.1007/s10639-017-9605-2

Akçayir, M., \& Akçayir, G. (2017). Advantages and challenges associated with augmented reality for education: A systematic review of the literature. Educational Research Review, 20(1), 1-11. https://doi.org/10.1016/j.edurev.2016.11.002

Araque N., \& Barrio J. (2010). Atención a la diversidad y desarrollo de procesos educativos inclusivos. Prisma Social, (4), 1-37. https://www.redalyc.org/pdf/3537/353744577013.pdf

Arksey, H., \& O'Malley, L. (2005). Scoping studies: towards a methodological framework. International Journal of Social Research Methodology, 8(1), 19-32. https://doi.org/10.1080/1364557032000119616

Awada, G. (2014). Instructional strategies for enhancing learning disabled students reading comprehension test performance. Universitat Rovira Virgil. https://eric.ed.gov/?id=EJ343893

Azuma, R., Baillot, Y., Behringer, R., Feiner, S., Julier, S., \& Maclntyre, B. (2011). Recent advances in augmented reality. Computer Graphics and Applications, 21(6), 34-47. https://doi.org/10.1109/38.963459

Bacca, J., Baldiris, S., Fabregat, R., \& Graf, S. (2014). Augmented reality trends in education: a systematic review of research and applications. Journal of Educational Technology \& Society, 17(4), 133-149. https://files.eric.ed.gov/fulltext/EJ1174807.pdf

Bacca, J., Baldiris, S., Fabregat, R., \& Kinshuk, S. (2014). Insights into the factors influencing students motivation in Augmented reality learning experiences in vocational and education and training. Frontier in Psychology, 9, 1486. https://doi.org/10.3389/fpsyg.2018.01486

Baragash, R., Al-samarrie, H., Azahrai, A., \& Alfarraj, O. (2020). Augmented reality in special education; A meta-analysis of single-subject design studies. European Journal of Special Needs Education, 35(3), 382-397. https://doi.org/10.1080/08856257.2019.1703548

Beetham, H., \& Share, R. (2013). Rethinking pedagogy for a digital age: Designing for 21st century learning (2nd edition). Routledge. https://doi.org/10.4324/9780203078952

Behmke, D., Kerven, D., Lutz, R., Paredes, J., Pennington, R., Brannock, E., Deiters, M., Rose, J., \& Stevens, K. (2018). Augmented reality chemistry: Transforming 2-D molecular representations into interactive 3D structures. Proceedings of the Interdisciplinary STEM Teaching and Learning Conference, 2(1), 3. https://doi.org/10.20429/stem.2018.020103

Benda, P., Ulman, M., \& Smejkalova, M. (2015). Augmented reality as a working aid for intellectual disabled persons for work in Horticulture. Agris Online Papers in Economic and Informatics, VII(4), 31-37. https://doi.org/10.7160/aol.2015.070403

Blattgerste, J., Renner, P., \& Pfeiffer, T. (2019). Augmented Reality Action Assistance and Learning for Cognitively Impaired People - A Systematic Literature Review. Proceedings of the 12th ACM International Conference on PErvasive Technologies Related to Assistive Environments (PETRA '19), June 5-7, 2019, Rhodes, Greece. ACM, New York, NY, USA (Article 4, pp. 270-279). https://doi.org/10.1145/3316782.3316789 
Bridges, S., Robinson, O., Stewart, E., Kwon, D., \& Mutua, K. (2019). Augmented reality: Teaching daily living skills to adults with intellectual disabilities. Journal of Special Education Technology, 35(1), 3-14. https://doi.org/10.1177/0162643419836411

Browder, D., Flowers, C., \& Wakeman, S. (2008). Facilitating participation in assessments and the general curriculum: Level of symbolic communication classification for students with significant cognitive disabilities. Assessment in Education: Principles, Policy \& Practice, 15(2), 137-151. https://doi.org/10.1080/09695940802164176

Cacciator, G. (2018). Video prompting delivered via augmented reality to teach transition related math skills to adults with intellectual disabilities (Unpublished doctoral dissertation), Brigham Young University. https://scholarsarchive.byu.edu/etd/6971/

Cai, S., Wang, X., \& Chiang, F. K. (2014). A case study of augmented reality simulation system application in a chemistry course. Computers in Human Behavior, 37, 31-40. https://doi.org/10.1016/j.chb.2014.04.018

Cakir, R., \& Krkmaz, O. (2019). The effectiveness of augmented reality environments on individual with special education needs. Education and Information Technologies, 24, 1631-1659. https://doi.org/10.1007/s10639-018-9848-6

Carnahan, C., Williamson, P., Hollingshead, A., \& Israel, M. (2012). Using technology to support balanced literacy for students with significant disabilities. Teaching Exceptional Children, 45(1), 20-29. https://doi.org/10.1177/004005991204500104

Carreon, A., Smith, S., \& Rowland, A. (2019). Augmented reality: Creating and implementing digital classroom supports. Journal of Special Education Technology, 35(2), 109-115. https://doi.org/10.1177/0162643419882423

Cate, C., David, F., Kim, B., McMahon, D., \& Wright, R. (2017). Examining augmented reality o improve navigation skills in postsecondary students with intellectual disability. Journal of Special Educating Technology, 32(1), 3-11. https://doi.org/10.1177/0162643416681159

Chang, Y., Kang, Y., \& Huang, P. (2014). An augmented reality (AR)-based vocational task prompting system for people with cognitive impairments. Research in Development Disabilities, 34(2013), 3049-23056. https://doi.org/10.1016/j.ridd.2013.06.026

Chen, C., Lee, I., \& Lin, L. (2015). Augmented reality based self-facial modeling to promote the emotional expression and social skills of adolescents with autism spectrum disorders. Research in Developmental Disabilities, 36, 396-403. https://doi.org/10.1016/j.ridd.2014.10.015

Cheng, K., \& Tsai, C. (2013). Affordances of augmented reality in science learning: Suggestions for future research. Journal of Science Education and Technology, 22(4), 449-462. https://doi.org/10.1007/s10956-012-9405-9

Cifuentes, S., García, S., Andrés-Sebastiá, M., Camba, J., \& Contero. M. (2016). Augmented reality experiences in therapeutic pedagogy: A study with special needs students [Paper presentation]. 2016 IEEE 16th International Conference on Advanced Learning Technologies (ICALT, 25-28 July, Austin, TX. https://doi.org/10.1109/ICALT.2016.23

Collins, A., \& Halverson, R. (2009). Rethinking education in the age of technology: The digital revolution and the schools. Teachers College Press. https://ssrn.com/abstract $=2064922$

Dalgarno, B., \& Lee, M. (2010). What are the learning affordances of3-D virtual environments? British Journal of Educational Technology, 41(1), 10-32. https://doi.org/10.1111/j.1467-8535.2009.01038.x 
Deshpande, A., \& Kim, I. (2018). The effects of augmented reality on improving spatial problem solving for object assembly. Advanced Engineering Informatics, 38, 760-775. https://doi.org/10.1016/J.AEl.2018.10.004

Diao, P., \& Shih, N. (2019). Trends and research issues of augmented reality studies in architectural and civil engineering education-A review of academic journal publications. Applied Science, 9, 1840. https://doi.org/10.3390/app9091840

Diegmann P., Schmidt-Kraepelin M., Eynden S., \& Basten D. (2015). Benefits of AR in educational environments-A systematic literature review. Wirtschaftsinformatik. http://aisel.aisnet.org/wi2015

Di-Serio, Á., Ibáñez, M., \& Kloos, C. (2013). Impact of an augmented reality system on students' motivation for a visual art course. Computers \& Education, 68, 586-596. https://doi.org/10.1016/j.compedu.2012.03.002

Dunleavy, M., Dede, C., \& Mitchell, R. (2009). Affordances and limitations of immersive participatory augmented reality simulations for teaching and learning. Journal of Science Education and Technology, 18(1), 7-22. http://doi.org.10.1007/s10956-008-9119-1

Eldenfria, A., \& Alsamarraie, H. (2019). Towards an online continuous adaptation mechanism (OCAM) for enhanced engagement: An EEG study. International Journal of Human-Computer Interaction, 35, 19601974. https://doi:10.1080/10447318.2019.1595303

Ferrer-Torregrosa, J., Torralba, J., Jimenez, M. A., García, S., \& Barcia, J. (2015). ARBOOK: development and assessment of a tool based on augmented reality for anatomy. Journal of Science Education and Technology, 24(1), 119-124. https://doi.org/10.1007/s10956-014-9526-4

Fridhi, A., Benzarti, F., Frihida, A., \& Amiri, H. (2018). Application of virtual reality and augmented reality in psychiatry and neuropsychology, in particular in the case of autistic spectrum disorder (ASD). Neurophysiology, 50(2018), 222-228. https://doi.org/10.1007/s11062-018-9741-3

Garzon, J., Pavon, J., \& Baldiris, S. (2019). Systematic review and meta-analysis of augmented reality in educational settings. Virtual Reality, 23, 447-459. https://doi.org/10.1007/s10055-019-00379-9

Gavish, N., Gutierrez, T., Webel, S., Rodriguez, J., Peveri, M., \& Bockholt, U. (2013). Evaluating virtual reality and augmented reality training for industrial maintenance and assembly tasks. Journal Interactive Learning Environment, 23(6), 778-798. https://doi.org/10.1080/10494820.2013.81521

Giglioli, I., Pallavicini, F., Pedroli, E., Serion, S., \& Riva, G. (2015). Augmented reality: A brand new challenge for the assessment and treatment of psychological disorders. Computational and Mathematical Methods in Medicine, 2015, 862942. https://doi.org/10/1155/2015/862942

Gomez-Puetra, M., Chiner, E., Meero-Perez, P., \& Lorenzo, G. (2019). Research review on augmented reality as an educational resource or people with intellectual disabilities. International Journal of Developmental and Educational Psychology Revista INFAD dePsicolgia, 3(1), 473. https://doi.org/10.17060/ijodaep.2019.n1.v3.1523

Hornecker E., \& Buur J. (2006). Getting a grip on tangible interaction: A framework on physical space and social interaction. In The SIGCHI conference on Human Factors in computing systems (pp. 437-446). ACM. https://doi.org/10.1145/1124772.1124838

Huang, J., Kinateder, M., DunN, M., Jarosz, W., Yang, X., \& Cooper, E. (2019). An augmented reality sin-reading assistant for users with reduced vision. PloS ONE, 14(1), e0210630. https://doi.org/10.1371/journal.pone.0210630

Ibanez, M., Di-Serio, A., Villaran, D., \& Kloos, C. (2014). Experimenting with electromagnetism using augmented reality: Impact on flow student experience and educational effectiveness. Computers \& Education, 71, 1-13. https://doi.org/10.1016/j.compedu.2013.09.004 
Jdaitawi, M. (2019). The effect of flipped classroom strategy on stduents learning outcomes. International Journal of Instruction, 12(3), 665-680. http://doi.org/10.29333/iji.2019.12340a

Jdaitawi, M. (2020a). Does flipped learning promote positive emotions in science education? A comparison between traditional and flipped classroom approaches. The Electronic Journal of e-Learning, 18(6), 516-524. http://doi.org/10.34190/JEL.18.6.004

Jdaitawi, M. (2020b). The effect of using problem-based learning upon students emotions towards learning and levels of communication skills in three different disciplines. Croatian Journal of Education, 22(1), 207-240. http://doi.org/10.15516/cje.v22i1.3215

Jones, P., Somoskeoy, T., Chow-Wing-Bom, H., \& Crabb, D. (2020). Seeing other perspectives: Evaluating the use of virtual and augmented reality to stimulate visual impairments (Open VisSim). Digital Medicine, 3, 32. https://doi.org/10.1038/s41746-020-0242-6

Karagozlu, D. (2018). Determination of the impact of Augmented Reality application on the success and problem-solving skills of students. Quality and Quantity, 52(5), 2393-2402. https://doi.org/10.1007/s11135-017-0674-5

Kellems, R., Cacciatore, G., \& Osborne, K. (2019). Using an augmented reality-based teaching strategy to teach mathematics to secondary students with disabilities. Career Development and Transition for Exceptional Individuals, 42(4), 253-258. http://doi.org/10.1177/2165143418822800

Khan, T., Jhnstn, K., \& Ophoff, J. (2019). The impact of an augmented reality application on learning motivation of students. Advances in Human-Computer Interaction, 2019, 7208494. https://doi.org/10.1155/2019/7208494

Kinateder, M., Gualtieri, J., Dunn, M., Mcoptom., Jarosz, W., Yang, X., \& Cooper, E. (2018). Using an augmented reality device as a distance-based vision aid-promise and limitations. Optom Vis Science. https://doi.org/10.1097/OPX.0000000000001232

Kitchenham, B. (2004). Procedures for performing systematic reviews. http://citeseerx.ist.psu.edu/viewdoc/summary?doi=10.1.1.122.3308

Klopfer, K., \& Squire, K. (2008). Environmental detectives-the development of an augmented reality platform for environmental simulations. Educational Technology Research and Development, 56(2), 203-228. https://doi.org/10.1007/s11423-007-9037-6

Kun, A., Meulen, H., \& van der Janssen, C. (2019). Calling while driving using augmented reality: Blessing or course? PRESENCE Virtual Augmented Reality, 27, 1-14. https://doi.org/10.1162/pres_a_00316

Kyza, E., \& Georgiou, Y. (2018). Scaffolding augmented reality inquiry learning: The design and investigation of the TraceReaders location-based, augmented reality platform. Interaction Learning Environment, 27, 211-225. https://doi.org/10.1080/10494820.2018.1458039

Leonardi, M., Bickenbach, J., Ustun, T., Kostanjsek, N., \& Chatterji, S. (2006). The definition of disability: what is in a name? The Lancet, 368(2006), 1219-1221. https://doi.org/10.1016/S0140-6736(06)69498-1

Lin C., Chai H., Wang J., Chen C., Liu Y., Chen C., et al. (2016a). Augmented reality in educational activities for children with disabilities. Displays, 42, 51-54. https://doi.org/10.1016/j.displa.2015.02.004

Lin, T., Duh, H., Li, N., Wang, H., \& Tsai, C. (2013). An investigation of learners' collaborative knowledge construction performances and behavior patterns in an augmented reality simulation system. Computers \& Education, 68, 314-321. https://doi.org/10.1016/j.compedu.2013.05.011

Lindsay G. (2018). Inclusive education theory and practice: what does this mean for paediatricians? Paediatrics and Child Health, 28, 368-373. https://doi.org/10.1016/j.paed.2018.06.002 
Lorenzo, G., Gomez-Puerta, M., Arraez-Vera, G., \& Lorenzo-Liedo, A. (2019). Preliminary study of augmented reality as an instrument for improvement of social skills in children with autism spectrum disorder. Education and Information Technologies, 24, 181-204. https://doi.org/10.1007/s10639-018-9768-5

Martín-Gutierrez, J., \& Fernandez, M. (2014). Applying augmented reality in engineering education to improve academic performance \& student motivation. International journal of engineering education, 30(3), 625-635.

McMahon, D., Cihak, D., \& Wright, R. (2015). Augmented reality as a navigation tool to employment opportunities for postsecondary education students with intellectual disabilities and autism. Journal of Research on Technology in Education, 47(3), 157-172. https://doi.org/10.1080/15391523.2015.1047698

Meyer, A., Rose, D., \& Gordon, D. (2014). Universal design for learning: Theory and practice. http://castpublishing.org/books-media/udl-theory-and-practice/

Mthembu, N. (2018). Information and Communication Technology (ICT) and its mixed reality in the learning sphere. International Journal of Virtual Augment Reality, 2, 26-37. https://doi.org/10.4018/IJVAR.2018070102

Oranç, C., \& Küntay, A. (2019). Learning from the real and the virtual worlds: Educational use of augmented reality in early childhood. International Journal of Child-Computer Interaction, 21, 104-111. https://doi.org/10.1016/J.IJCCI.2019.06.002

Ozdemir, M., Sahin, C., Arcagok, S., \& Demir, M. (2018). The effect of augmented reality applications in the learning process: A meta-analysis study. Eurasian Journal of Educational Research, 74(2018), 165-186. https://doi.org/10.14689/ejer.2018.74.9

Pradibta, H. (2018). Augmented reality: Daily prayers for preschooler student. International Journal of Interactive Mobile Technology, 12(1), 151-158. https://doi.org/10.3991/ijim.v12i1.7269

Quandt, M., Knoke, B., Gorldt, C., Freitag, M. \& Thoben, K. (2018). General Requirements for Industrial

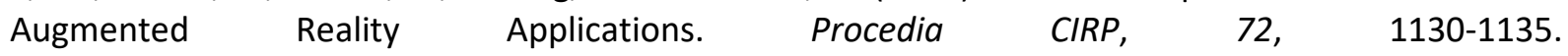
https://doi.org/10.1016/j.procir.2018.03.061

Quintero, J., Baldiris, S., Rubira, R., Ceron, J., \& Veez, G. (2019). Augmented reality in educational inclusion. A systematic review on the last decade. Frontier in Psychology, 10, 1835. https://doi.org/10.3389/fpsyg.2019.01835

Quiroga, P. M. R. (2010). La evolución de la atención a la diversidad del alumnado de educación primaria a lo largo de la historia [The evolution of attention to the diversity of primary education students throughout history]. Review Digital Professional Ens, 8, 1-15. https://www.feandalucia.ccoo.es/docu/p5sd7241.pdf

Quqandi, E., Joy, M., Rushton, M., \& Drumm, I. (2018). Mobile augmented reality in nursing educational environment. In 2018 10th Computer Science and Electronic Engineering (CEEC) (pp. 266-269). IEEE. https://doi.org/10.1109/CEEC.2018.8674182

Radu, I. (2012). Why should my students use AR? A comparative review of the educational impacts of augmented reality. In IEEE International Symposium on Mixed and Augmented Reality (ISMAR) (pp. 313-314). IEEE. https://doi.org/10.1109/ISMAR.2012.6402590

Rizov, T., \& Rizov, E. (2015). Augmented reality as a teaching tool in higher education. International Journal of Cognitive Research in Science, Engineering and Education, 3(1), 7-16. https://doi.org/10.23947/2334-8496-2015-3-1-7-15 
Sampaio, D., \& Almeida, P. (2016). Pedagogical strategies for the integration of augmented reality in ICT teaching and learning processes. Procedia Computer Science, 100, 894-899. https://doi.org/10.1016/j.procs.2016.09.240

Savelsbergh, E., Prins, G., Rietbergen, C., Fechner, S., Vaessen, B., Draijer, J., \& Bakker, A. (2016). Effects of innovative science and mathematics teaching on student attitudes and achievement: A meta-analytic study. Educational Research Review, 19, 158-172. https://doi.org/10.1016/j.edurev.2016.07.003

Sheehy K., Ferguson R., \& Clough, G. (2014). Augmenting learners: educating the transhuman. In K. Sheeh, R. Ferguson, \& G. Clough (Eds.), Augmented Education (pp. 137-158). Palgrave Macmillan. https://doi.org/10.1057/9781137335814_8

Shelton, B. (2003). Augmented reality and education: current projects and the potential for classroom learning. New Horizons Learning, 9(1).

Sirakaya, M., \& Sirakaya, A. (2018). Trends in educational augmented reality studies: A systematic review. Malaysian Online Journal of Educational Technology, 6, 60-74. https://doi.org/10.17220/mojet.2018.02.005

Sirakaya, M., \& Sirakaya, D. (2020). Augmented reality in STEM education: A systematic review. Interactive Learning Environments, 1-14. https://doi.org/10.1080/10494820.2020.1722713

Smith, C., Cihak, D., Kim, B., McMahon, D., \& Wright, R. (2017). Examining augmented reality to improve navigation skills in postsecondary students with intellectual disability. Journal of Special Education Technology, 32(1), 3-11. https://doi.org/10.1177/0162643416681159

Sommerauer, P., \& Müller, O. (2014). Augmented reality in informal learning environments: A field experiment in a mathematics exhibition. Computers \& Education, 79, 59-68. https://doi.org/10.1016/j.compedu.2014.07.013

Sugiura, A., Kitama, T., Toyoura, M., \& Mao, X. (2018). The use of augmented reality technology in medical specimen museum tours. Anatomy Science Education. https://doi.org/10.1002/ase.1822

Taryadi, D., \& Kurniawan, I. (2018). The improvement of autism spectrum disorders on children communication ability with PECS method multimedia augmented reality based. Journal of Physics: Conference Series, 47(1), 1-8. https://doi.org/10.1088/1742-6596/947/1/012009

Tekedere, H. \& Goker, H. (2016). Examining the effectiveness of augmented reality application in education: A meta-analysis. International Journal of Environmental \& Science Education, 11(16), 9469-9481.

Walker, Z., McMahon, D., Rosenblatt, K., \& Arner, T. (2017). Beyond Pokémon: Augmented reality is a universal design for learning tool. Sage Open, 7(4), 1-8. https://doi.org/10.1177/2158244017737815

Westwood, P. \& Graham, L. (2009). Inclusion of students with special needs: Benefits and obstacles perceived by teachers in New South Wales and South Australia. Australian Journal of Learning difficulties, 8(1), 3-15. https://doi.org/10.1080/19404150309546718

Wojciechowski, R. \& Cellary, W. (2013). Evaluation of learners' attitude toward learning in ARIES augmented reality environments. Computers \& Education, 68, 570-585. https://doi.org/10.1016/j.compedu.2013.02.014

Wu, H., Lee, S., Chang, H., \& Liang, J. (2013). Current status, opportunities and challenges of augmented reality in education. Computers \& Education, 62, 41-49. https://doi.org/10.1016/j.compedu.2012.10.024

Yuliono, T., \& Rintayati. P. (2018). The Promising Roles of Augmented Reality in Educational Setting: A Review of the Literature. International Journal of Educational Methodology, 4(3), 125-132. https://doi.org/10.12973/ijem.4.3.125 
Zhao, Y., Hu, M., Hashash, S., \& Azenkot, S. (2017). Understanding low vision people's visual perception on commercial augmented reality glasses [Paper presentation]. CHI Conference, May 6-11, 2017, Denver, CO, USA. https://doi.org/10.1145/3025453.3025949

Correspondence: Malek Turki Jdaitawi, Imam Abdulrahman Bin Faisal University, Saudi Arabia.

E-mail:mtmustafa@iau.edu.sa 